\title{
NOTAS SOBRE ESTADO SUBSIDIARIO Y LEGISLACIÓN LABORAL EN CHILE
} $(1973-2013)$

\author{
Roberto Andrés Cerón Reyes* \\ Universidad de Chile \\ Universidad Central de Chile
}

\section{INTRODUCCIÓN}

Hablar de la ley laboral no es fácil. Su mera enunciación viene cargada con un sentido que rebasa con creces, lo estrictamente jurídico, pues su objeto -las relaciones de trabajo- es estudiado por una serie de disciplinas que forman parte de las Ciencias Sociales: Economía, Filosofía, Sociología y demás. Acá la abordaremos en su faz más cercana para quien cultiva el Derecho, la jurídica, pero en una dimensión distinta a la habitualmente usada por los autores y prácticos, quienes suelen emplear un razonamiento puramente dogmático, sin ninguna otra consideración.

Existe, en efecto, una inclinación en la doctrina chilena por estudiar la norma laboral en su dimensión "práctica", es decir, en su aplicación inmediata, en su interacción con los operadores jurídicos, etc., lo que es de suyo apropiado para el campo de la praxis, pero insuficiente para comprender, desde su más hondas raíces, el rumbo y sentido de la ley laboral y, también, del Derecho del Trabajo. En este sentido, es incalculable el valor que puede agregar la perspectiva históricojurídica, entendiéndose por ella no sólo la utilidad del elemento histórico consagrado en el artículo 20 del Código Civil, y que ha guiado algunos trabajos en la disciplina ${ }^{1}$, sino que también un entendimiento de la legalidad laboral en sí, enquistada en el complejo cuadro de lo jurídico en una época y momento histórico determinado, pues la historia del derecho, a través de las formas jurídicas que adopta el derecho, escarba y descubre la dimensión cultural, económica, política y social de una comunidad².

Históricamente la ley laboral en Chile surgió como una "ley privilegio", en oposición a la "ley mandato uniforme" que es aplicada a toda las personas y a la generalidad de las relaciones jurídicas. Desde mediados de la segunda década del siglo XX diversos sectores de la población reclaman y reivindican para sí un estatuto jurídico que recoja sus intereses y conquistas sociales, pues el derecho vigente no comprendía las nuevas realidades de la época y, asimismo, era incapaz de ofrecer soluciones a tales problemáticas. Al decir de Moran, se asistió a una révolte des faits contre le code, o sea, a una revuelta de los hechos contra el derecho ${ }^{3}$, lo que decantó en la promulgación de un sinnúmero de legislación ajena a los tradicionales principios del Derecho Civil, fenómeno

\footnotetext{
* Abogado. Ayudante de Derecho del Trabajo e Historia del Derecho, Facultad de Derecho, Universidad de Chile. Profesor de Historia del Derecho, Facultad de Ciencias Jurídicas y Sociales, Universidad Central de Chile. Contacto: robertoceronr@gmail.com

Espinoza Arriagada, Natalia Paz y Gaete Santelices, Victoria Elisa. Evolución del concepto de responsabilidad de la empresa principal en el sistema de subcontratación chileno: análisis de la jurisprudencia judicial y administrativa. Tesis (Licenciado en Derecho). Santiago, Chile: Universidad de Chile, Facultad de Ciencias Jurídicas y Sociales, 2009, passim.

Stolleis, Michael. La Historia del Derecho como obra de arte. Madrid, España: Editorial Comares, 2009, passim. Bravo Lira, Bernardino. "Historia e Historia del Derecho. Cosas que por calladas, se olvidan. En torno a la obra histórica de Gonzalo Vial", en: Boletín de la Academia Chilena de la Historia año LXXVI, julio-diciembre 2010, no 119, vol. II., pp. 9-18.

3 Morin, Edgard. La révolte des faits contre le code. París, Francia, 1920.
} 
conocido como descodificación, consistente en "la sustracción al código [civil], operada por la legislación especial, de ciertas materias para regularlas de una manera diferente en función de determinados fines socialmente valiosos"4. A través del naciente Derecho del Trabajo comienza a configurarse, poco a poco, una legislación dirigida a regular las condiciones de trabajo e higiene de aquellos más desvalidos -proletariado-, para cubrir, ya en 1931, a los trabajadores de los demás sectores.

En otras palabras, una legislación que viene desde abajo y es sancionada por el gobernante de turno, instalado constitucional o extraconstitucionalmente en el poder 5 .

Dicha "ley privilegio" no es otra cosa que el velo proteccionista, consustancial e inherente a toda norma laboral el cual, junto a otros elementos, constituye el sustrato histórico del Derecho del Trabajo ${ }^{6}$ y que, con mayor o menor intensidad, se conserva en la generalidad de las legislaciones laborales actuales.

Por otra parte, en el caso del iuslaboralismo chileno existen ciertas orientaciones metodológicas que en su afán de ir a la vanguardia con los hechos, comprende la legislación laboral en conjunción con la realidad misma, sin exageraciones ideológicas ni recetas uniformes y aplicables para todos los pueblos y en todos los tiempos. En esa dirección queremos encaminar nuestra brevísima aproximación a la legalidad laboral, pero incorporando un nuevo tópico de estudio: las relaciones entre el modelo que adopta un Estado y la legislación laboral. Y cuando hablamos de "modelo" aludimos a su finalidad cardinal en torno al cual se articula su papel en la vida de un país.

En Chile la legislación laboral emergió en medio de un Estado modernizador, caracterizado por promover la felicidad del pueblo, y que se remonta a la época de la monarquía en Chile. A lo largo del siglo XX el Estado modernizador:

“...intentó realizar el ideal dieciochesco [felicidad del pueblo] sucesivamente de dos maneras: el Estado gendarme del liberalismo que, con el propósito de imponer la libertad a los ciudadanos, somete sus actividades a una regulación uniforme, y cuando éste fracasa, el Estado de bienestar que, con el propósito de restablecer la seguridad, somete las actividades de los ciudadanos a una regulación restrictiva"7.

Y un Estado modernizador en su vertiente de bienestar y, agreguemos, desarrollista, es el que vio nacer al Derecho del Trabajo y a la ley laboral. De ahí que la legislación dictada conforme a este ideal decimonónico propendió a anteponer la protección de las personas por sobre la libertad

\footnotetext{
GuZmán Brito, Alejandro. "Codificación, descodificación y recodificación del Derecho Civil chileno", en: Revista de Derecho y Jurisprudencia y Gaceta de los Tribunales. Tomo XC, no 1: enero-abril, año 1993, p. 42. IRTI, Natalino. La edad de la descodificación. Madrid, España: Editorial José Bosch, 1992, passim.

Aún no se estudia en profundidad la relación que existe en Chile entre los gobiernos militares y el Derecho del Trabajo. Tangencialmente y a propósito de la codificación laboral véase CASTRO, José Francisco. "La codificación del Derecho del Trabajo en Chile", en: Revista Laboral Chilena, no 203, 2012, pp. 72-80.

6 Para Adrián Goldin los elementos que configuran un Derecho del Trabajo básico histórico son: 1) El contrato de trabajo como expresión de libertad, pero a su vez de sometimiento (dependencia); 2) Esfuerzos por poner límites al sometimiento; 3) Mejora de esos límites; 4) Un nivel óptimo de libertad compartida (vgr. flexibilidad); 5) Desigualdad como presupuesto fáctico y como contrapartida de igualdad de dignidades; 6) Construcción de equilibrios en este escenario. Goldin, Adrián. Conferencia dictada en el marco de apertura del Congreso Mundial de Derecho del Trabajo. Santiago, Chile, septiembre 2012.

Bravo Lira, Bernardino. "Del Estado modernizador al Estado subsidiario. Trayectoria institucional de Chile 1891-1995”, en: Revista de Estudios Histórico-Jurídicos, XVII, Valparaíso, Chile, 1995, p. 195.
} 
de las mismas, explicándose así, y sin perjuicio de otras aristas, la frondosa legislación laboral del período (1924-1973).

Sin entrar en detalles, la legalidad laboral se fue tiñendo paulatinamente con el manto ideológico de aquellos sectores que reclamaban tal o cual reivindicación social, producto de la intromisión excesiva de los partidos políticos, situación que llegó a su paroxismo en la primera época de las planificaciones globales (1964-1973) ${ }^{8}$, donde los sujetos de la relación laboral -trabajador y empleador- llegaron a encontrarse en posiciones abiertamente antagónicas.

Junto al abrupto final del Estado modernizador en 1973, sucumbió también el régimen de gobierno, instalándose uno de carácter nacional bajo la forma de una Junta Militar. En cuanto al tema que nos convoca, se implanta una nueva idea de Estado, el subsidiario. Bajo su signo la legislación laboral se rearticula conforme al papel que juegan las personas, las familias y los cuerpos intermedios, quienes son llamados a perseguir por su propia cuenta su desarrollo material y espiritual y, a través de éste, el del país. De ahí que la norma laboral cobre un nuevo sentido, un tanto distinto a la del período anterior, puesto que debe coexistir con la noción de subsidiariedad. Veamos las notas más sobresalientes de este proceso que se proyecta hasta nuestros días. Al ser un primer acercamiento, el trabajo está sujeto a enmiendas y adiciones, conforme se avanza en el estado de la investigación.

\title{
1. ESTADO SUBSIDIARIO Y LEY LABORAL EN CHILE
}

Como ya enunciamos, en 1973 se hundió definitivamente el Estado modernizador en Chile, rearticulándose, ahora, bajo la forma de un Estado subsidiario. Su fisonomía es descrita por Bravo Lira:

\begin{abstract}
"El punto de partida es la renuncia de este Estado subsidiario a la pretensión liberal y socialista de regular desde arriba la vida de la población. En consecuencia, no sólo tolera las organizaciones intermedias, sino que apela al empuje de las personas y a la autorregulación de dichas organizaciones. Institucionalmente el Estado subsidiario se asienta sobre el juego recíproco entre el núcleo fundamental del Estado -constituido en Chile desde el siglo XVII sobre la base de la trilogía Presidente, Judicatura y Fuerzas Armadas- y las organizaciones intermedias, que a lo largo del siglo XX se han convertido en factor decisivo en la vida nacional. De esta suerte ni el Estado pretende dirigir desde arriba todas las actividades de la población ni los diversos sectores de la misma utilizar al Estado para que les asegure condiciones de subsistencia que ellos no son capaces de procurarse por su esfuerzo. Naturalmente, esto vale para tiempos normales y no excluye medidas transitorias de auxilios en casos de emergencia" ${ }^{\prime}$.
\end{abstract}

De ahí el repliegue y reducción del aparato estatal que corre a la par con la ampliación de la capacidad creativa de las personas y los grupos intermedios, ya que el nuevo signo bajo el cual navegará el Estado descansará en una premisa antropológica enraizada en el actuar preferente, pero no excluyente, del hombre y de las asociaciones a las que pertenece, en las actividades pro-

GÓNGORA, Mario. Ensayo histórico sobre la noción de Estado en Chile en los siglos XIX y XX. Santiago, Chile: Editorial Universitaria, 2006, pp. 280 y ss. A propósito de las restricciones al derecho de propiedad y la reanudación de faenas en la huelga véase BRAHM García, Enrique. Propiedad sin libertad: Chile 1925-1973. Santiago, Chile: Universidad de los Andes, Colección Jurídica, 1999, pp. 225 y ss.

Bravo LiRa, Bernardino. "Del Estado modernizador... (n. 7), p. 229. 
ductivas y en la búsqueda del bien común, pues, como comunidad política, son los más idóneos para alcanzar los fines que ellos se proponen. Se transita, así, de la persona al servicio del Estado al Estado al servicio de la persona. En el plano constitucional, se manifestará en el principio de subsidiariedad. En palabras de Alejandro Silva Bascuñán:

"Conforme a dicho principio, el Estado, en la búsqueda del bien común, asume un papel menos directo y preponderante en la satisfacción de las necesidades colectivas, desde que ha de actuar en subsidio de aquellas actividades que los particulares no pueden, no deben, o no quieren asumir, con lo cual se confía a la libre iniciativa privada ejecutar diversas tareas que antes estaban reservadas exclusivamente a organismos del aparato estatal"10.

Esta nueva orientación del Estado se tradujo en una reestructuración, en diversos planos, de las actividades del país (Administración, Estado empresario, modelo económico, etc.). Por su parte, las relaciones laborales y su regulación no quedaron ajenas a estas transformaciones. Era necesario dejar atrás aquella normativa dictada en el período anterior, enraizada en un modelo económico fracasado y con una normativa laboral ideologizada por los partidos de turno que cooptaron las dirigencias sindicales, y que terminó imponiendo normas protectoras que asfixiaron la libertad de las personas, al punto de conculcársela a sus propios destinatarios ${ }^{11}$. Ahora la protección laboral cobra una nueva significación, pues no gira en torno a sí misma, sino que se articula "en" la libertad de las personas y grupos intermedios para emprender. Dicho de otro modo, la ley laboral sigue siendo una ley especial y protectora, pero ella convive, no sin tensiones, con la libertad del sujeto y de las más diversas asociaciones, a quienes no se les podrá impedir la búsqueda, por sus propios medios, de su felicidad, y del bien común del país.

Lo anterior no es baladí. Si centramos nuestra atención en estas premisas fácil es advertir que el modelo laboral instaurado hace casi treinta años se mantiene, sin exageraciones, incólume, pues se aviene mejor a la naturaleza de las relaciones laborales. Su solidez se reafirma en cada reforma a la norma laboral, donde siempre se deja a cubierto la libertad, ya de empresa, de trabajo o sindical. De esto se habla y es objeto de crítica constantemente por algunos autores de la disciplina ${ }^{12}$ pero sin percatarse, ni mucho menos preguntarse, el por qué y el cómo este modelo perdura y extiende sus influencia exitosamente hasta hoy. Miradas así las cosas podemos hablar de "un" Código del Trabajo: el de las libertades de empresa, trabajo y sindical. Normativamente ellas conviven y se superponen unas a otras y, más importante aún, son el origen y medida de las normas laborales que contiene el código.

\footnotetext{
10 Silva Bascuñán, Alejandro. Tratado de Derecho Constitucional. Tomo XIII. Santiago, Chile: Editorial Jurídica de Chile, 2010, pp. 374-375. Para una reflexión política véase GARCía-Huidobro, Joaquín. ¿Para qué sirve la política? Santiago, Chile: Instituto Res Pública, 2012, pp. 68-73.

11 Casos paradigmáticos son el sindicato único de obreros y la sindicalización obligatoria.

12 Por ejemplo, el profesor José Luis Ugarte habla del "modelo laboral heredado de la dictadura”, el académico Eduardo Caamaño Rojo, a propósito de la negociación colectiva, "del fantasma de los Chicago Boys", y la profesora Irene Rojas del "Plan Laboral impuesto autoritariamente durante el régimen militar”. Véase UGarte Cataldo, José Luis. El nuevo Derecho del Trabajo. Santiago, Chile: Editorial Universitaria, 2004, passim; CAAMaÑo Rojo, Eduardo. "Las materias objeto de negociación colectiva y la libertad sindical: el fantasma de los "Chicago Boys" a 30 años del Plan Laboral". En: CaAmaño Rojo, Eduardo y Pereira Lagos, Rafael (Coordinadores). Estudios de Derecho del Trabajo y de la Seguridad Social. Doctrina chilena y extranjera. Tomo IV. Santiago, Chile: AbeledoPerrot - Thomson Reuters, 2012, pp. 189-215; y RojAs Miño, Irene. "Las reformas laborales al modelo normativo de negociación colectiva del Plan Laboral”, en: Revista Ius et Praxis, vol. 13, nº 2, 2007, Talca, pp. 196 y ss.
} 
Recorrer en detalle la trayectoria de la ley laboral durante estos treinta años supera los límites de esta primera aproximación. Nos conformaremos con exponer brevemente sus momentos más relevantes y en un estilo marcadamente descriptivo, pues el tema aún admite reestudios.

Primero, se impone una política de desmantelamiento del orden laboral anterior, vía derogación de toda norma atentatoria contra la libertad de empresa, de trabajo y sindical. Segundo, la articulación de estas tres libertades en la normativa laboral y también en la Constitución de 1980. Tercero, la promulgación de un Código del Trabajo, en sus versiones refundidas, cada vez que la cantidad de normas modificadas o la magnitud de la enmienda así lo requiera -Código de 1987, 1994 y 2001-. Finalmente, el período comprendido entre el año 2002 y principios de 2012 corre la misma suerte, cuestión que queda en evidencia en las historias de los artículos reformados durante esta última década. El modelo laboral es el mismo, pero rearticulado según las exigencias de los tiempos; y que reposa, en último término, en las libertades mencionadas, indispensables para la realización de los fines asignados a las personas y a los grupos intermedios.

\section{TRAYECTORIA DE LA LEY LABORAL EN CHILE}

$$
\text { (1973-2013) }
$$

\subsection{HaCIA UN DESMANTELAMIENTO DE LA NORMATIVA LABORAL (1973-1978)}

El gobierno instalado en 1973 optó, no sin vacilaciones ni dobleces iniciales, por emprender una profunda readecuación de las normas laborales, a tono con el nuevo modelo de economía social de mercado que pretendía instaurar. La ruptura con el modelo laboral anterior y la normativa que lo sustentaba significó, a la postre, una verdadera "revolución" en la materia, siendo necesario, antes, "un arduo trabajo de limpieza y liberalización del mercado del trabajo en Chile"13. Así, se procedió con los excesos propios de una revolución y no de una reforma, al desmantelamiento y neutralización de la normativa laboral vigente.

En este sentido se comprende la normativa laboral del período. Los decretos leyes $\mathrm{N}^{\circ} 12$ y No 133, de 1973, que cancelaron la personalidad jurídica y disolvieron la Central Única de Trabajadores; decreto ley No 198, de 1973, que prorrogó las directivas sindicales vigentes al 11 de septiembre de 1973 regulando, además, las actividades sindicales, con ciertas restricciones; decreto ley № 307, de 1974, que estableció un sistema único de prestaciones familiares para todos los trabajadores; decreto ley No 603, que instituyó un subsidio de cesantía; decreto ley № 670, de 1974, que reguló algunos aspectos de las remuneraciones y estableció normas sobre Comisiones Tripartitas Consultivas, las que dejaron de funcionar en 1979, terminando así la intromisión del Estado en esta materia; decretos leyes o 676 y No 930, ambos de 1975, que modificaron la ley oo 16.455 sobre terminación de la relación de trabajo, que puso fin al anterior régimen de despido -sin expresión de causa-, siendo procedente sólo por causa justificada e incorporando entre ellas la causal de necesidades de la empresa, indispensable para una adecuación de la organización empresarial a los vaivenes del mercado; decreto ley No 1.446 sobre Estatuto de Capacitación y Empleo, para capacitar a los trabajadores al interior de la empresa; decreto ley No 2.346, de 1978, que declaró ilícitas y disolvió varias organizaciones sindicales, a tono con la creciente oposición al régimen imperante y su visión conservadora de la relación laboral; y el decreto ley No 2.347, que declaró ilícitas y contrarias al orden público a los grupos o personas que, sin personería para ello, representasen a los trabajadores ${ }^{14}$.

Piñera, José. La Revolución Laboral en Chile -3o edición-. Santiago, Chile: Editorial Zig-Zag, 1990, p. 45.

Walker Errázuriz, Francisco. Derecho de las Relaciones Laborales. Santiago, Chile: Editorial Universitaria, 2003, pp. 108-109. 


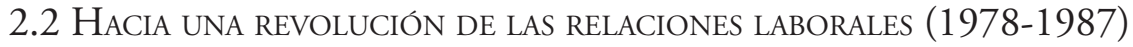

A tono con la estrategia de desarrollo económico y el papel asignado a las personas y los cuerpos intermedios, el segundo paso en la construcción de la nueva institucionalidad laboral consistió en la dictación de nuevas y renovadas normas del trabajo. A juicio de los economistas "ellas llevaron a Chile a una posición de avanzada en el concierto latinoamericano y mundial en lo que se refiere a la desregulación y flexibilidad del mercado del trabajo" ${ }^{15}$. Y precisamente los economistas avizoraron la readecuación de la ley laboral. Evocando la normativa laboral de antaño, el Ministro del Trabajo de la época, José Piñera, afirmó:

"La normativa laboral chilena fue hija de "corazones sangrantes" y de razonamientos débiles. Los textos de estudios parten invariablemente con inflamadas declaraciones de redención social. Pero nada dicen acerca de cómo mejorar en la realidad las condiciones de vida de la gente. No obstante que el mercado es una realidad eminentemente económica -puesto que juegan un rol clave los conceptos de costo, productividad, competencia y demanda- el lenguaje que se usa es de fibra inconfundiblemente emocional. No hay político, no hay abogado con "sensibilidad social", no hay agitador, no hay vicario "progresista" ni hay comunicador social de "avanzada", que no pueda dar en cualquier momento una encendida conferencia sobre el tema de la equidad en las relaciones laborales. Pero nunca estas proclamas contienen soluciones viables y coherentes a los problemas; son sólo expresión de buenos deseos"16.

Por lo que el giro en materia económica, arraigado también en la nueva concepción de Estado, pavimentó el camino para las leyes promulgas y publicadas en el período. Veamos las más importantes:

- $\quad$ Decreto ley No 2.200 , de 1978, sobre contrato de trabajo y protección de los trabajadores que, entre otras cosas, suprimió las diferencias laborales entre empleados y obreros. A juicio de Thayer "fue sentida por la población como una respuesta social, económica y política que no debía demorarse" ${ }^{\text {"17. }}$. En materia de despido reincorporó el desahucio como causal de terminación del contrato de trabajo, con indemnización al trabajador equivalente a un mes de remuneración por año de servicio ${ }^{18}$.

- $\quad$ Decretos leyes No 2544 y 2545, de 9 de febrero de 1979, sobre libertad sindical y fijación de normas sobre cotización y recaudación de cuotas en los sindicatos, conocidas como "leyes aperitivo" del Plan Laboral. Sobre el particular:

\footnotetext{
Lizama Portal, Luis. "El derecho del trabajo chileno durante el siglo XX", en: Revista Chilena de Derecho del Trabajo y de la Seguridad Social, vol. 2, no 4, segundo semestre 2011, Santiago, p. 120.

15 Coloma, Fernando y Rojas, Patricio. "Evolución del Mercado Laboral en Chile: Reformas y Resultados”. En: Larraín, Felipe y Vergara, Rodrigo. (coordinadores). La Transformación Económica de Chile. Santiago, Chile: Centro de Estudios Públicos, 2000, p. 499.

16 Piñera, José, op. cit. (n. 13), p. 25.

17 Thayer Arteaga, William. Dimensión Histórica del Código del Trabajo. Santiago, Chile: Universidad del Desarrollo, Facultad de Derecho, 2008, p. 38.

18 Posteriormente, en 1981, la ley No 18.618 modificó el decreto ley No 2.200. En efecto, mantuvo el desahucio unilateral, pero redujo la indemnización a un mes por año de servicio con un tope de cinco años para los trabajadores contratados a partir de la fecha de publicación de la ley. Por su parte, la ley No 18.372 de 1984, eliminó la causal de necesidades de la empresa, reincorporada al Código del Trabajo en la década del noventa.
} 
“...estos decretos leyes autorizaron que los empleadores descontaran por planilla las cuotas para el sindicato y las entregaran a la directiva sindical cuando la mayoría absoluta de los trabajadores afiliados al sindicato así lo acordare en votación secreta o el propio trabajador lo autorizare por escrito. Nada de presunciones o de arbitrios de la autoridad...[y de]...votación abierta en asamblea" 19 .

Decretos leyes № 2.756 y 2.758 , de 1979 , sobre organizaciones sindicales y negociación colectiva, respectivamente -Plan Laboral-. Con ellas se instaló la libertad de asociación del trabajador a los sindicatos de empresa que estableció la ley. La libertad sindical se imponía ante el sindicalismo politizado de viejo cuño.

Decreto ley No 2.757, de 1979, sobre asociaciones gremiales.

Decreto ley No 3.648, de 1981, que suprimió los tribunales del trabajo, radicando la competencia en materia laboral en los juzgados civiles $^{20}$.

Ley $N^{o}$ 18.010, de 14 de agosto de 1981, conocida como "Ley rastrillo", que derogó ciertas leyes y estatutos especiales y/o gremiales.

Ley No 18.032, de 1981, que estableció normas sobre trabajadores portuarios.

Deslizando un dejo de crítica Lizama sostiene que “...la legislación laboral del gobierno militar incorpora contenidos ideológicos que se apartan de los tradicionales del derecho laboral chileno, proteccionista y tutelar de los derechos de los trabajadores..." ${ }^{21}$. Visto de otra manera, la normativa laboral del período, sin abandonar su afán protector, convive con normas que trasuntan, al plano de las relaciones de trabajo, la libertad de las personas. Así se infiere si miramos las reformas en conjunto, y no en comparación con la normativa anterior que, según ya hemos dicho, obedeció a otros parámetros -Estado modernizador-, ahora incompatibles con el modelo de Estado subsidiario y una economía social de mercado. Asimismo, se reconoce fácilmente el influjo de la libertad de empresa, de trabajo y sindical en las leyes ya mencionadas, libertades todas reconocidas en la Constitución Política de $1980^{22}$.

\subsection{Hacia el Código del Trabajo (1987-2001)}

La nueva normativa laboral, dispersada en las leyes arriba enunciadas requirió, junto a las enmiendas para una mejor aplicación, su reunión en un solo cuerpo legal. Refundirla en un Código. Como ya insinuamos al principio de este trabajo, las bases del ordenamiento jurídico laboral descansarán, de aquí en adelante, en la libertad de empresa, de trabajo y sindical. El resto, sin perjuicio de las componendas políticas, las conquistas y reivindicaciones de los actores de la relación de trabajo -empleador y trabajador-, será una constante rearticulación de la ley en torno a ellas. Y cuando hablamos de rearticulación es porque ellas coexisten en un juego de tira y aflojas, en un permanente reacomodamiento. Según esto, los mal llamados “Códigos” de 1987, 1994 y 2001 son una fiel expresión del intento de reafirmar y equilibrar una libertad frente a otra. Baste una rápida mirada por las leyes reformadas y las razones esgrimidas para comprobar lo que proponemos.

\footnotetext{
PIÑERA, José, op. cit. (n. 13), p. 22.

20 La ley No 18.510 de 1986, restableció los juzgados del trabajo y los procedimientos laborales.

21 Lizama Portal, Luis, op. cit. (n. 14), p. 124.

22 Artículos 19 No 20-24 (Orden Público Económico), 19 No 16 y 19 No 19, respectivamente.
} 


\subsubsection{Código de 1987: la libertad de empresa se reafirma}

En palabras de Thayer el Código de 1987 “...buscó hacer posible el funcionamiento de un sistema laboral individual y colectivo compatible con una economía social de mercado, donde no hubiera distingos entre empleados y obreros, y el Estado se enmarcara en su papel subsidiario y no compitiera con la empresa privada, que debía operar como gran motor del crecimiento económico"23. Razones que ya hablan de la superposición de la libertad de empresa por sobre la de trabajo y sindical, lo que se reafirmó cuando se procedió a realizar las reformas que cristalizaron en el refundido Código del Trabajo del año 1994. Los textos incorporados al Código de 1987 fueron, entre otros:

- $\quad$ Títulos V y VI del Libro I del primitivo Código del Trabajo, que regula los contratos de embarco, gente de mar y portuarios.

- Decreto ley No 2.200, de 1978, sobre contrato de trabajo y protección de los trabajadores.

- $\quad$ Decreto ley No 2.201, de 1978, sobre mérito ejecutivo de las actas suscritas ante los inspectores del trabajo.

- $\quad$ Decreto ley No 1.446, de 1976, sobre Estatuto de Capacitación y Empleo.

- $\quad$ Decreto ley No 2.759, de 1979, que reguló varias materias. Entre ellas la relativa a la responsabilidad subsidiaria del dueño de la empresa, obra o faena respecto de los contratistas.

- $\quad$ Ley No 16.744, de 1968, sobre accidentes de trabajo y enfermedades profesionales.

- $\quad$ Decreto ley No 2.756, de 1978, sobre organización sindical.

- $\quad$ Decreto ley № 2.758, de 1979, sobre negociación colectiva.

- $\quad$ Decreto ley No 2.977, de 1979, sobre Cuerpo Arbitral.

- $\quad$ Ley No 18.510 , sobre juzgados del trabajo y procedimientos laborales.

- $\quad$ Ley No 14.972, de 1962, sobre multas por infracciones laborales.

- $\quad$ Decreto ley No 676, de 1974, sobre facultades del Director del Trabajo.

- $\quad$ Decreto con fuerza de ley No 2, de 1967, sobre organización y funciones del Director del Trabajo $^{24}$.

\subsubsection{Código de 1994: la libertad de trabajo se reafirma}

La vuelta a los gobiernos cortos y de elección periódica, así como las diversas observaciones críticas hechas a la legislación laboral vigente, propiciaron el ambiente para una nueva reforma al Código del Trabajo. Según Lizama, el gobierno de la época definió una estrategia denominada "crecimiento con equidad" que "suponía conciliar en el plano laboral los intereses de los empleadores y trabajadores en un clima de crecimiento y estabilidad" 25 . En otras palabras, la conciliación entre libertad de empresa y de trabajo. Así, se dictaron entre 1990 y 1993 una serie de leyes, refundidas en $1994^{26}$ :

\footnotetext{
23 Thayer Arteaga, William. "Orígenes, evolución y perspectivas del Derecho Laboral chileno", en: Estudios Públicos, nº 54 (otoño 1994), p. 227.

24 Ibid., p. 229. Humeres Magnan, Héctor y Humeres Noguer, Héctor. Derecho del Trabajo y de la Seguridad Social-Decimocuarta edición-. Santiago, Chile: Editorial Jurídica de Chile, 1994, pp. 79-80.

25 Lizama Portal, Luis, op. cit. (n. 14), p. 127.

26 Las referencias en Thayer Arteaga, William. “Orígenes,... (n. 23), pp. 231-234. Lizama Portal, Luis, op. cit. (n. 14), pp. 127128.
} 
- Ley No 19.010, de 1990, que estableció normas sobre terminación del contrato de trabajo y estabilidad en el empleo. Esta ley suprimió el régimen de desahucio del Código de 1987, estableciéndose la obligación del empleador de invocar una causa justificada para terminar el contrato de trabajo, manteniendo el desahucio para los gerentes, trabajadores de casa particular y personal de exclusiva confianza del empleador; se reincorporó la causal de necesidades de la empresa; se instituyó un régimen indemnizatorio a todo evento para los trabajadores de casa particular, aumentaron las indemnizaciones legales de 150 -5 meses- a 330 días - 11 meses- de remuneración, entre otras.

- Ley No 19.049, de 1991, sobre centrales sindicales. Es una ley complementaria de la anterior, cuyo objeto era allanar el reconocimiento de la Central Única de Trabajadores, adherente del gobierno de la época.

- $\quad$ Ley No 19.069, de 1991, sobre organizaciones sindicales y negociación colectiva.

- $\quad$ Ley No 19.250, de 1993, que modificó los Libros I, II y V del Código del Trabajo y otros cuerpos legales. Esta ley reformó, entre otros aspectos, el contrato individual de trabajo, contratos especiales de trabajo, las prácticas antisindicales y el procedimiento laboral.

Nuevamente, miradas en su totalidad las reformas avanzaron a un adecuado equilibrio entre la libertad de empresa y la libertad de trabajo, a través de la incorporación de normas que garantizan un adecuado ejercicio de esta última ${ }^{27}$. En opinión de Lizama, que compartimos:

“...resulta evidente que la política laboral del presidente Aylwin se encaminaba a propiciar relaciones bipartitas y equilibradas entre trabajadores y empresarios, reservando el rol del Estado exclusivamente a la regulación y fiscalización de las normas del trabajo. Las reformas laborales no tenían como propósito reemplazar el modelo de flexibilidad laboral adoptado durante el gobierno militar, sino que exclusivamente introducirle correcciones destinadas a rescatar el papel tutelar del derecho del trabajo"28.

\subsubsection{Código de 2001: la libertad sindical se reafirma}

Fruto de una dilatada y complicada tramitación, en el año 2001 se publicó la ley No 19.759 que modificó el Código del Trabajo en innumerables materias: nuevas formas de contratación, derecho de sindicación, libertad sindical, derechos fundamentales del trabajador, etc.

El contenido abarcó cien artículos definitivos y ocho de carácter transitorios, alterando una gran cantidad de normas del referido código. A juicio de Humeres Noguer, y en base a lo dispuesto en la historia de la ley:

"Los objetivos que persigue la ley [No 19.759] son los de erradicar la discriminación laboral, introducir nuevos tipos de contrato para generar mayores oportunidades laborales, impulsar la libertad sindical con resguardos efectivos ante prácticas antisindicales y promover una negociación colectiva más extensa y equilibrada..."29.

\footnotetext{
27 Thayer Arteaga, William. "Orígenes, ... (n. 23), p. 237.

28 Lizama Portal, Luis, op. cit. (n. 14), p. 129.

29 Humeres Noguer, Héctor. Reforma laboral. Ley No 19.759. Santiago, Chile: Editorial Jurídica de Chile, 2001, p. 12.
} 
No obstante el abanico de materias que comprendió esta enmienda, la libertad sindical viose robustecida. Los números son indicativos: del total de las normas modificadas, un $50 \%$ dice relación con las organizaciones sindicales, un $20 \%$ a la negociación colectiva y un $30 \%$ a materias de derecho individual de trabajo ${ }^{30}$. Es decir, un $70 \%$ de sus normas buscó, directa e indirectamente, el fortalecimiento de ella en el ordenamiento e institucionalidad laboral.

Lo anterior iba en plena concordancia con la normativa internacional. En efecto, la libertad sindical se encuentra contenida en los convenios No 87 y No 98 de la OIT, dictados en el año 1948 y 1949, respectivamente; y ratificados en Chile el 1 de febrero del año 1999, dos años antes de la reforma. Asimismo, el ordenamiento jurídico nacional, en virtud de lo dispuesto en los artículos $5^{\circ}$ y $19 \mathrm{~N}^{\circ} 19$ de la constitución, comprende la aplicación de tales convenios, por su asimilación bajo la forma de tratados internacionales y su protección expresa como garantía constitucional ${ }^{31}$. De modo que aquel "derecho de los trabajadores y sus agrupaciones para organizarse y defender sus intereses" ${ }^{32}$ se hizo realidad, con más fuerza que nunca, en el orden jurídico laboral.

La amplitud de esta reforma nos impide reseñar en detalle las materias introducidas. Menos aún enunciar uno a uno los artículos. Veamos, sí, algunas de las innovaciones en materia de organizaciones sindicales y negociación colectiva.

\section{Organizaciones sindicales}

Amplía el espectro de clases de sindicatos (artículo 216) y ministros de fe en materia sindical (artículo 218); redimensiona los fines de las organizaciones sindicales (artículo 220), eliminándose, entre ellos, la restricción del sindicato para representar a los trabajadores en la negociación colectiva; extiende el fuero sindical de los trabajadores que constituyen un sindicato (artículo 221) y el plazo para comunicar al empleador la nueva directiva sindical; reduce los quórum para la constitución de sindicatos de empresa (artículo 227); aumenta el número de delegados sindicales (artículo 229); regulación de materias varias, a propósito de los estatutos sindicales (artículos 231 a 233 bis); nueva regulación del número de directores que integran el directorio sindical (artículos 234 a 238); incorpora nuevas figuras antisindicales (artículo 289); entre otras.

\footnotetext{
$30 \quad$ Ibid., p. 12. Walker ERrázuriz, Francisco. "Breve análisis de algunas de las recientes reformas en materia de relaciones individuales del trabajo introducidas por la ley Núm. 19.759 de 2001 al Código del Trabajo Chileno”. En: KurCZYN VilLalobos, Patricia y Puig Hernández, Carlos Alberto (coordinadores). Estudios jurídicos en homenaje al doctor Néstor de Buen Lozano. México, Universidad Nacional Autónoma de México, 2003, pp. 799 y ss.

31 Convenio 87 sobre "la libertad sindical y protección del derecho de sindicación" y Convenio 98 sobre "el derecho de sindicación y negociación colectiva”. Para un análisis de la negociación colectiva y la libertad sindical véase CaAmaño Rojo, Eduardo y UGARTE Cataldo, José Luis. Negociación colectiva y libertad sindical. Un enfoque crítico. Santiago, Chile: Legal Publishing, 2008, pp. 13 y ss. Una visión histórica y jurídica se encuentra en Mengod Gimeno, Rosa María. Libertad sindical. Efectos de la promulgación de los convenios 87 y 98 de la OIT, en la legislación chilena. Santiago, Chile: Departamento de Derecho del Trabajo y de la Seguridad Social, Facultad de Derecho de la Universidad de Chile, 2007, 32 pp.

32 Gamonal Contreras, Sergio. Derecho colectivo del trabajo. Santiago, Chile: Editorial LexisNexis, 2007, p. 60. Otra definición, donde se explicitan sus atributos se encuentra en CaAmaño Rojo, Eduardo, Ugarte Cataldo, José Luis, op. cit. (n. 31), pp. 14-15. En efecto, señalan que es "el derecho que asiste a los trabajadores para constituir organizaciones, afiliarse o desafiliarse a ellas, a darse su propia normativa sin intervención de terceros y, especialmente, el derecho al ejercicio de la actividad sindical por medio de aquellas acciones tendientes a la defensa y promoción de los intereses que le son propios, en particular, la negociación colectiva y la huelga”.
} 


\section{Negociación colectiva}

Modifica el campo de aplicación de la negociación colectiva no reglada (artículo 314 y 314 bis); regula el derecho a la información de los trabajadores (artículo 315); nuevos plazos, ahora ampliados, de respuesta a proyecto de contrato colectivo y comunicación a los demás trabajadores (artículos 320 y 329); negociación colectiva de trabajadores agrícolas de temporada (artículo 314 bis, letras a, b, y c, y 351); limitación a la extensión del contrato colectivo (artículo 347); prohibición de reemplazo de trabajadores en huelga (artículo 381), salvo cumplimiento de los requisitos legales; entre otras.

\section{SÍNTESIS Y CONCLUSIÓN}

La trayectoria de la ley laboral es un proceso que, mirado en clave histórico jurídica, discurrirá inagotablemente, sin interrupciones y a la par con los procesos sociales, económicos y culturales, salvo que su cuerpo de normas se fije sin más o se derogue para siempre. Esto es imposible. La ley laboral, al regular un fenómeno tan cambiante como el trabajo se ve obligada, para ser eficaz, a ir a la zaga de los hechos; de recoger de la realidad social imperante en una época determinada los elementos que definen el trabajo asalariado. En el caso del Código del Trabajo la norma laboral debe regular, al menos, una de las tantas formas de trabajo existentes, el trabajo dependiente ${ }^{33}$.

Sin perjuicio de lo anterior, hay ciertos elementos constitutivos que forman parte de su sustrato inicial e histórico. Uno de ellos es la protección a la persona, la cual a partir de 1973 convive con una concepción de Estado, el subsidiario. Bajo su signo la legislación laboral se rearticuló conforme al papel que juegan las personas, las familias y los cuerpos intermedios, quienes son llamados a perseguir por su propia cuenta propia su desarrollo material y espiritual y, a través de este, el del país. Ahora la protección laboral cobra una nueva significación, pues no gira en torno a sí mismo, sino que se articula "en" la libertad de las personas y grupos intermedios para emprender. En el caso de la institucionalidad laboral, tales libertades son la de empresa, de trabajo y sindical. En torno a la protección y las libertades mencionadas descansa la actual normativa laboral. No avizoramos un cambio de modelo pues quizás este sea su éxito: el respeto a las libertades del empleador y del trabajador. En suma y al decir de Walker “...cabe hacer presente que la institucionalidad laboral chilena vigente... proviene de lo construido durante el gobierno militar, con la modificaciones realizadas en los últimos años..." ${ }^{34}$.

Las constantes reformas legislativas no han hecho sino reafirmar el orden ya instituido, otorgándole una solidez admirada por algunos y criticada por otros. En el caso de las reformas emprendidas entre los años 2002 y principios de $2012^{35}$ la constante es la misma. Se fortalece la libertad de empresa al regular una nueva forma de contratación laboral: la subcontratación y las empresas de servicios transitorios; la libertad sindical al regular el destino del patrimonio del sindicato; y la libertad de trabajo al regular de forma novedosa ciertas jornadas. Los ejemplos se podrían multiplicar en uno y otro caso.

\footnotetext{
33 Thayer Arteaga, William. "Entrevista", en: Revista Chilena de Derecho del Trabajo y de la Seguridad Social, vol. 2, no 4, segundo semestre 2011, Santiago, p. 214.

34 Walker Errázuriz, Francisco. Derecho de... (n. 14), p. 117.

35 Durante este período se publicaron 52 enmiendas al Código del Trabajo que, en número de artículos, conforman más de un tercio del actual articulado del código.
} 


\section{BIBLIOGRAFÍA}

Brahm García, Enrique. Propiedad sin libertad: Chile 1925-1973. Santiago, Chile: Universidad de los Andes, Colección Jurídica, 1999.

Bravo Lira, Bernardino. "Del Estado modernizador al Estado subsidiario. Trayectoria institucional de Chile 18911995”, en: Revista de Estudios Histórico-Jurídicos, XVII, Valparaíso, Chile, 1995.

Bravo Lira, Bernardino. "Historia e Historia del Derecho. Cosas que por calladas, se olvidan. En torno a la obra histórica de Gonzalo Vial", en: Boletín de la Academia Chilena de la Historia año LXXVI, julio-diciembre 2010, no 119, vol. II., pp. 9-18.

CaAmaño Rojo, Eduardo y Ugarte Cataldo, José Luis. Negociación colectiva y libertad sindical. Un enfoque crítico. Santiago, Chile: Legal Publishing, 2008.

CAAMAÑo Rojo, Eduardo. "Las materias objeto de negociación colectiva y la libertad sindical: el fantasma de los "Chicago Boys” a 30 años del Plan Laboral”. En: Caamaño Rojo, Eduardo y Pereira Lagos, Rafael (Coordinadores). Estudios de Derecho del Trabajo y de la Seguridad Social. Doctrina chilena y extranjera. Tomo IV. Santiago, Chile: AbeledoPerrot - Thomson Reuters, 2012, pp. 189-215.

Castro, José Francisco. "La codificación del Derecho del Trabajo en Chile”, en: Revista Laboral Chilena, n² 203, 2012, pp. $72-80$.

Coloma, Fernando y Rojas, Patricio. “Evolución del Mercado Laboral en Chile: Reformas y Resultados”. En: Larraín, Felipe y Vergara, Rodrigo. (coordinadores). La Transformación Económica de Chile. Santiago, Chile: Centro de Estudios Públicos, 2000.

Espinoza Arriagada, Natalia Paz y Gaete Santelices, Victoria Elisa. Evolución del concepto de responsabilidad de la empresa principal en el sistema de subcontratación chileno: análisis de la jurisprudencia judicial y administrativa. Tesis (Licenciado en Derecho). Santiago, Chile: Universidad de Chile, Facultad de Ciencias Jurídicas y Sociales, 2009.

Gamonal Contreras, Sergio. Derecho colectivo del trabajo. Santiago, Chile: Editorial LexisNexis, 2007.

García-Huidobro, Joaquín. ¿Para qué sirve la política?. Santiago, Chile: Instituto Res Pública, 2012.

Goldin, Adrián. Conferencia dictada en el marco de apertura del Congreso Mundial de Derecho del Trabajo. Santiago, Chile, septiembre 2012.

Góngora, Mario. Ensayo histórico sobre la noción de Estado en Chile en los siglos XIX y XX. Santiago, Chile: Editorial Universitaria, 2006.

GuZmán Brito, Alejandro. “Codificación, descodificación y recodificación del Derecho Civil chileno”, en: Revista de Derecho y Jurisprudencia y Gaceta de los Tribunales. Tomo XC, nº 1: enero-abril, año 1993.

Humeres Magnan, Héctor y Humeres Noguer, Héctor. Derecho del Trabajo y de la Seguridad Social -Decimocuarta edición-. Santiago, Chile: Editorial Jurídica de Chile, 1994.

Humeres Noguer, Héctor. Reforma laboral. Ley No 19.759. Santiago, Chile: Editorial Jurídica de Chile, 2001.

IRTI, Natalino. La edad de la descodificación. Madrid, España: Editorial José Bosch, 1992.

Lizama PorTal, Luis. "El derecho del trabajo chileno durante el siglo XX", en: Revista Chilena de Derecho del Trabajo $y$ de la Seguridad Social, vol. 2, no 4, segundo semestre 2011, Santiago.

Mengod Gimeno, Rosa María. Libertad sindical. Efectos de la promulgación de los convenios 87 y 98 de la OIT, en la legislación chilena. Santiago, Chile: Departamento de Derecho del Trabajo y de la Seguridad Social, Facultad de Derecho de la Universidad de Chile, 2007, 32 pp.

Morin, Edgard. La révolte des faits contre le code. París, Francia, 1920.

Piñera, José. La Revolución Laboral en Chile -3o edición-. Santiago, Chile: Editorial Zig-Zag, 1990.

RoJAS MiÑo, Irene. "Las reformas laborales al modelo normativo de negociación colectiva del Plan Laboral", en: Revista Ius et Praxis, vol. 13, no 2, 2007, Talca. 
Silva Bascuñán, Alejandro. Tratado de Derecho Constitucional. Tomo XIII. Santiago, Chile: Editorial Jurídica de Chile, 2010.

StOlleis, Michael. La Historia del Derecho como obra de arte. Madrid, España: Editorial Comares, 2009.

Thayer Arteaga, William. "Orígenes, evolución y perspectivas del Derecho Laboral chileno", en: Estudios Públicos, no 54 (otoño 1994).

Thayer Arteaga, William. Dimensión Histórica del Código del Trabajo. Santiago, Chile: Universidad del Desarrollo, Facultad de Derecho, 2008.

Thayer Arteaga, William. "Entrevista", en: Revista Chilena de Derecho del Trabajo y de la Seguridad Social, vol. 2, no 4, segundo semestre 2011, Santiago.

Ugarte Cataldo, José Luis. El nuevo Derecho del Trabajo. Santiago, Chile: Editorial Universitaria, 2004.

Walker Errázuriz, Francisco. "Breve análisis de algunas de las recientes reformas en materia de relaciones individuales del trabajo introducidas por la ley Núm. 19.759 de 2001 al Código del Trabajo Chileno”. En: Kurczyn Villalobos, Patricia y Puig Hernández, Carlos Alberto (coordinadores). Estudios jurídicos en homenaje al doctor Néstor de Buen Lozano. México, Universidad Nacional Autónoma de México, 2003, pp. 799 y ss.

Walker Errazuriz, Francisco. Derecho de las Relaciones Laborales. Santiago, Chile: Editorial Universitaria, 2003. 